\title{
OBJETIVO E CARACTERÍSTICAS QUALITATIVAS DA INFORMAÇÃO CONTÁBIL: UMA ANÁLISE COMPARATIVA DO SATTA E ESTRUTURA CONCEITUAL PARA O RELATÓRIO FINANCEIRO (ED/2015/3)
}

\section{OBJECTIVE AND QUALITATIVE CHARACTERISTICS OF ACCOUNTING INFORMATION: A COMPARATIVE ANALYSIS OF SATTA AND CON- CEPTUAL FRAMEWORK FOR FINANCIAL REPORTING (ED/2015/3)}

\begin{abstract}
RESUMO
O estudo pretende desenvolver uma análise evolutiva da Teoria da Contabilidade, no que tange ao objetivo e às características qualitativas da informação contábil, por meio de análise comparativa entre os documentos SATTA e Estrutura Conceitual do IASB. A metodologia utilizada foi a pesquisa descritiva e documental, posto que o estudo baseou-se na análise especifica dos documentos Statement on Accounting Theory and Theory Acceptance (SATTA) e Conceptual Framework for Financial Reporting, em fase de conclusão pelo International Accounting Standards Board (IASB). Diante do normativo mais recente sobre o entendimento do IASB sobre a Estrutura Conceitual, por meio do Basis for Conclusions on the Exposure Draft Conceptual Framework for Financial Reporting - ED/2015/3, este estudo dará destaque ao capítulo 2, que trata das características qualitativas da informação financeira útil. Conclui-se que o SATTA apresentou conceitos teóricos consolidados em 1977, que foram legitimados e mantidos nas atuais Normas Internacionais de Contabilidade.
\end{abstract}

Palavras-chave: Teoria da Contabilidade; Características Qualitativas; SATTA; IASB; Conceptual Framework.

\begin{abstract}
This study intends to develop an evolutionary analysis of the Accounting Theory, regarding the objective and the qualitative characteristics of accounting information, through a comparative analysis between the documents: SATTA and IASB Conceptual Framework. The methodology used was the descriptive and documentary research, since the study was based on the specific analysis of the documents: Statement on Accounting Theory and Theory Acceptance - SATTA and the Conceptual Framework for Financial Reporting in phase of conclusion by the International Accounting Standards Board - IASB. In the light of the most recent normative on the IASB's understanding of the its Conceptual Framework, through the Basis for Conclusions on the Draft Conceptual Framework for Financial Reporting - ED / 2015/3, this study will highlight Chapter 2, which deals with the Qualitative Characteristics of Financial Information. This analysis concluded that SATTA presented theoretical concepts consolidated in 1977 that were legitimized and maintained in the current International Accounting Standards.
\end{abstract}

Keywords: Accounting Theory; Qualitative Characteristics; SATTA; IASB; Conceptual Framework.

\begin{abstract}
Nara Cristina Ferreira Mendes
Doutoranda em Ciências Contábeis na Universidade de Brasília (UnB). Mestre em Gestão Econômica de Finanças Públicas pela Universidade de Brasilia. Especialista em Contabilidade com ênfase em International Financial Reporting Standards - IFRS pela UnB. Auditora da UnB. Possui experiência na área de Contabilidade Aplicada ao Setor Público, Finanças Públicas e Auditoria. Contato: Campus Universitário Darcy Ribeiro, Asa Norte, Brasilia DF, CEP: 70.910-900. E-mail: naracfm@gmail.com
\end{abstract}

\section{José Matias Pereira}

Pós-Doutor em Administração na Universidade de São Paulo (USP). Doutor em Ciências Políticas pela Universidade Complutense de Madrid. Professor de Administração Pública e Finanças Públicas e Pesquisador associado do Programa de Pós-Graduação em Ciências Contábeis da Universidade de Brasília. Possui experiência na área de Administração Pública, Finanças Públicas e Economia Política. Contato: Campus Universitário Darcy Ribeiro, Asa Norte, Brasília - DF, CEP: 70.910-900. E-mail: matias@unb.br

\section{Rafael Martins Noriller}

Doutor em Ciências Contábeis pela Universidade de Brasilia (UnB). Mestre em Administração pela UFMS Graduado em Ciências Contábeis pela UFGD. Docente do curso de Ciências Contábeis na Universidade Federal da Grande Dourados (UFGD). Contato: Rodovia Dourados-Itahum km 12, Zona Rural, Dourados - MS, CEP: 79.800-000. E-mail: rafael.mnoriller@gmail.com

\footnotetext{
Josimar Pires da Silva

Doutorando em Ciências Contábeis pela Universidade de Brasília (UnB). Mestre em Ciências Contábeis pela Universidade de Brasília (UnB). Especialista em Gestão Financeira, Controladoria e Auditoria pela Fundação Getúlio Vargas (FGV). Docente do curso de Ciências Contábeis na Universidade Federal da Grande Dourados (UFGD). Contato: Rua Ranulfo Saldivar, 242 Parque Alvorada, MS, CEP: 79.823-420. E-mail: josimarnx@yahoo.com.br
} 


\section{INTRODUÇÃO}

A evolução da teoria da contabilidade, até o início de 1950, aconteceu a partir de princípios e postulados contábeis (PATON, 1922; PATON; LITTLETON, 1940), necessitando, antes de tudo, compreender qual era o verdadeiro objetivo da contabilidade (VATTER, 1963). Para Hendriksen e Van Breda (2000), a necessidade de se estabelecer o propósito da contabilidade, antes de se aprofundar em princípios e postulados, despertou o interesse da American Accounting Association (AAA).

Por meio de um estudo intitulado como A Statement of Basic Accounting Theory (ASOBAT), a AAA (1966, p. 1) caracterizou a contabilidade como "o processo de identificação, mensuração e comunicação de informações econômicas para permitir julgamentos e decisões por parte dos usuários da informação”. Segundo Niyama (2014), o ASOBAT foi o documento mais influente publicado pela AAA. O referido estudo deixa evidente a importância do atendimento aos usuários da informação contábil, ponto fundamental e já destacado anteriormente por teses e pesquisas (RIAHI-BELKAOUI, 2004).

Além do ASOBAT, caracterizado como um documento acadêmico da teoria da contabilidade, cabe destacar o Accounting Principles Board n. ${ }^{\circ} 4$ (APB4), documento com uma perspectiva profissional do American Institute of Certified Public Accountants (AICPA), de 1970, que apresenta aspectos consagrados até os dias atuais, como os objetivos qualitativos da contabilidade (NIYAMA; SILVA, 2013). Em virtude da constituição do AICPA, formado principalmente por profissionais práticos, o conteúdo desta obra evidenciou o ponto de vista destes, em detrimento do ponto de vista acadêmico, proposto no ASOBAT.

Em 1973, o Comitê Executivo da AAA iniciou um projeto com o objetivo de fornecer informações sobre a aceitação da Teoria da Contabilidade, por meio da consolidação das mudanças encontradas nos últimos 10 anos, de modo a identificar perspectivas, ferramentas e técnicas de análise. O projeto resultou no SATTA, publicado em 1977, como um documento educacional para estudantes do pensamento contábil. Apesar de não ser um documento da Teoria da Contabilidade, muito contribuiu para o seu avanço, posto que efetuou a análise histórica e compilou as teorias existentes, ressaltando semelhanças e divergências (AAA, 1977).

Por sua vez, a Estrutura Conceitual (EC) dos Relatórios Financeiros é uma importante ferramenta para descrever normas com base em conceitos consistentes, motivo pelo qual o IASB atualizou e melhorou os fundamentos da EC em 2018. Gordon et al. (2015) apoiam o ponto de vista da EC no que diz respeito ao propósito de divulgação ligado às características qualitativas das informações financeiras reportadas.

Diante da necessidade de melhorias na informação contábil, proposta pelo IASB, e a importância do SATTA para a contabilidade, tem-se a seguinte questão de pesquisa: Houve evolução histórica da Teoria da Contabilidade, no que tange aos conceitos de objetivo e às características qualitativas da informação financeira útil, na comparação do SATTA com a Estrutura Conceitual? Para atender ao problema de pesquisa, o presente estudo possui o objetivo de desenvolver uma análise evolutiva da Teoria da Contabilidade, no que tange ao objetivo e às características qualitativas da informação financeira útil, por meio de análise comparativa entre os documentos SATTA e Estrutura Conceitual (ED/2015/3) do IASB.

Pesquisas prévias têm destacado a relevância da EC em diferentes abordagens. Algumas pesquisas se concentraram em demonstrar a trajetória da Teoria Contábil desde a década de 1920 até a atualidade - principalmente nos EUA -, evidenciando o caminho percorrido e as contribuições e contradições surgidas, advindas da relação entre as entidades: AAA, AICPA, Securities and Exchange Commission (SEC) e Financial Accounting Standards Board (FASB) (Niyama, Rodrigues Junior, Espiridião, \& Aragão, 1999; Oliveira, 2003; Oliveira \& Carvalho, 2006; Schipper, 2003; Zeff, 1984, 1999, 2007, 2013, 2014a, 2014b), culminando na emissão da EC do FASB e, posteriormente, do IASB.

Outras pesquisas destacaram a relação entre a EC e as normas e práticas contábeis adotadas, identificando as consequências e divergências existentes, bem como as necessidades de mudanças no arcabouço teórico, tendo em vista a busca por qualidade da informação contábil (Bradbury, 2003; Dennis, 2006; El-Essely, 1987; Gore, 1989; Hines, 1991; Nussbaumer, 1992; Paulo, 2002; Whittington, 2008; Xiao \& Pan, 1997).

Esta pesquisa complementa a literatura existente acerca da EC, relacionando-a com aspectos específicos evidenciados no SATTA, representando o pensamento do comitê da AAA, naquele momento, de modo que se possa identificar a possível influência na EC.

Estudos contábeis anteriores não dedicaram atenção necessária à relação entre o SATTA e a Estrutura Conceitual do IASB e as possíveis implicações dessa relação para os diversos agentes. De outro modo, quanto à EC, as pesquisas em contabilidade se concentravam antes, exclusivamente, na trajetória histórica em busca por Princípios Contábeis - principalmente a evolução da Teoria Contábil nos EUA entre a década de 1920 e a emissão do referencial conceitual do FASB -, e na aplicação prática da EC, principalmente com foco nas divergências com relação às normas vigentes. Essas pesquisas, em sua maioria, foram realizadas com base no referencial conceitual do FASB vigente na data de cada uma delas.

Em virtude das recentes mudanças relativas à EC, elevado destaque tem sido atribuído a essa produção pelo IASB e pelos demais normatizadores, tendo em vista a promoção do padrão contábil baseado em princípios. Como as alterações são ainda recentes, não foram encontradas pesquisas anteriores que se propuseram a investigar a nova Estrutura Conceitual, sobretudo a influência de uma produção específica. Neste estudo, pretende-se explorar o SATTA em busca dos elementos elencados no Conceptual Framework for Financial Reporting do IASB, a fim de descrever a evolução dos conceitos na visão da AAA e do IASB, bem como as implicações dessa relação. 
Desse modo, essa pesquisa pode ser útil para a academia e demais agentes, pois pode demonstrar o pensamento da AAA que culminou na inclusão de alguns aspectos da EC e, por outro lado, dar sustentação a outras pesquisas relativas à Teoria da Contabilidade e à EC, complementando o corpo de pesquisas existentes.

Kam (1990) atenta para o fato de a contabilidade reportar informações para o usuário diante do aumento da complexidade evolutiva das transações econômicas. Niyama (2014) expõe, ainda, que a contabilidade se torna informativa e com "qualidade" quando atinge a necessidade da maioria dos usuários, que podem ser os mais diversos possíveis. Para o IASB (2015a), a estrutura conceitual precisa atentar para melhorias, buscando atingir a necessidade desses usuários. Por sua vez, o SATTA, apesar de não ser um documento da Teoria da Contabilidade, apresentou pontos importantes dessa teoria.

Assim, este estudo foi estruturado em 5 (cinco) seções, quais sejam: introdução, referencial teórico (trata do SATTA e da Estrutura Conceitual em fase de conclusão pelo IASB), metodologia (procedimentos metodológicos adotados na pesquisa), seguida pela quarta seção, que realiza uma análise comparativa entre as alterações conceituais existentes entre ambos os documentos, no que tange ao objetivo e às características qualitativas da informação financeira útil. Por fim, aprensenta-se a quinta e última seção, que aborda as considerações finais e as sugestões para futuras pesquisas.

\section{REFERENCIAL TEÓRICO}

O presente capítulo apresenta uma breve contextualização sobre os documentos: o SATTA e a Estrutura Conceitual (ED/2015/3), em fase de conclusão pelo IASB. Neste item, serão evidenciados aspectos relacionados ao objetivo e às características qualitativas da informação visando viabilizar uma comparação futura quanto ao avanço da Teoria da Contabilidade, no que tange ao referido tema.

\subsection{Statement on Accounting Theory and Theory Acceptance (SATTA)}

Em 1977, foi publicado um documento elaborado pelo Comitê Executivo da AAA, um comitê de visão acadêmica, com o objetivo de fornecer informações sobre a aceitação da Teoria da Contabilidade. O projeto, que teve início em 1973, resultou no SATTA, um documento educacional para estudantes do pensamento contábil, contudo, esse não é um documento da Teoria da Contabilidade.

O documento buscou evidenciar uma base atraente para especificar o conteúdo dos relatórios financeiros, com o objetivo de dispor, de forma clara e objetiva, do acúmulo de literatura da Teoria da Contabilidade. Segundo Peasnell (1978) o documento não apresentou avanços, no que se refere a uma aceitação universal de apenas uma teoria da contabilidade.

O objetivo primário do SATTA foi verificar o grau em que as teorias contábeis fornecem uma base teórica para determinar o conteúdo dos relatórios financeiros externos e para a resolução de controvérsias contábeis. Contudo, o estudo concluiu que não existia uma teoria básica universalmente aceita. Assim, o documento buscou explicar o motivo da incapacidade de se alcançar um fechamento teórico por parte da comunidade contábil. Dentre os pontos mais relevantes do documento, cabe destacar o fato de os teóricos concordarem quanto ao objetivo central da contabilidade, que é definido como "a prestação sistemática de dados econômicos sobre os relatórios da entidade" (AAA, 1977).

Segundo a AAA (1977), há divergência no conceito dos termos "usuário" e "meio ambiente". No que tange ao termo "usuários", alguns teóricos compreendem que o termo se refere aos proprietários de uma entidade, já para outros teóricos, o conceito também inclui os credores, os empregadores, as autoridades reguladoras e de tributação, as instituições de caridade e o público em geral. E, ainda, sob uma perspectiva mais ampla, além dos agentes relacionados acima, os "usuários" seriam todos os membros de uma sociedade, de modo a representar um conjunto universal de usuários, no que se refere à necessidade do uso das informações contábeis.

Ademais, os usuários homogêneos e os heterogêneos (que concordam entre si) possuem a mesma demanda quanto aos dados contábeis que lhe são úteis, ensejando uma simples resolução de problemas contábeis. Assim, o atendimento dessa demanda de usuários possui uniformidade, o que facilita ao profissional contábil o fornecimento de informações úteis a esse grupo de indivíduos. Por outro lado, quando há heterogeneidade de usuários, esses não apresentam uniformidade de demanda por informação, tampouco concordam quanto às informações contábeis que lhe são úteis. Nesses casos, a resolução de problemas contábeis se torna complexa (AAA, 1977).

Quanto à definição do termo "meio ambiente", compreende-se que ele é o ambiente no qual os usuários e os preparadores dos dados contábeis se comportam, o qual se divide em 3 (três) classes, quais sejam: existência de múltiplas fontes concorrentes sobre a entidade, natureza do cenário multipessoa (subdividido em interação com o mercado e interação sem o mercado - externalidades) e atributos dos processos contábeis e do controle de tais processos, conforme a Figura 1. 
Figura 1: Questões ambientais

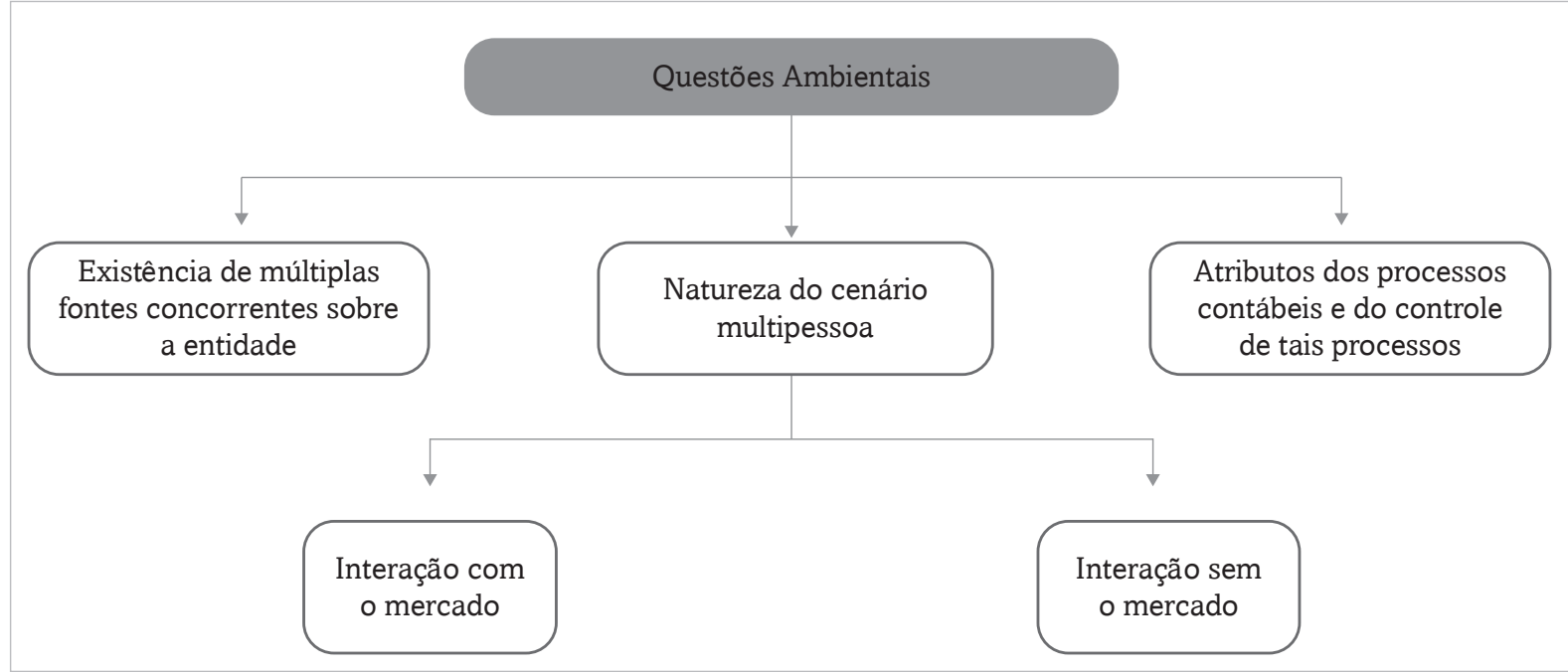

Fonte: Elaborado a partir de AAA (1977)

Tais divergências quanto à definição de termos dificultam a consolidação de uma Teoria da Contabilidade universalmente aceita. Assim, o SATTA conclui que não há uma teoria rica o suficiente para abranger a gama de especificações dos termos "usuário" e "meio ambiente" de forma eficaz e que não há uma Teoria da Contabilidade de forma consistente na literatura, havendo uma coletânea de teorias que partem de definições distintas quanto aos termos "usuários" e "meio ambiente". A partir desses cenários, cabe destacar Bublitz et al. (2015), que afirmam que o consenso é uma tarefa árdua.

Nessa linha, Iudícibus e Martins (2015) afirmam que, apesar de diversas pesquisas em contabilidade serem realizadas, existe uma ausência de uma tendência central para os trabalhos. Já Iudícibus, Beuren e Santos (2016) destacam que a Teoria da Contabilidade pode ser observada por diversas abordagens, atentando para a ausência de uma única teoria capaz de atender às necessidades específicas da contabilidade. Niyama (2014) complementa afirmando que a contabilidade apresenta um conjunto de teorias multidisciplinares.

No que se refere às abordagens relativas à Teoria da Contabilidade, segundo Chambers (1965), a história do pensamento contábil não é uma história de desenvolvimento, resultando em episódios desconectados. Assim, no intuito de identificar avanços na Teoria da Contabilidade, o SATTA identificou 3 (três) abordagens de teorias básicas dominantes, quais sejam: o Modelo Clássico, o Modelo de Utilidade da Decisão e o Modelo da Economia da Informação.

O Modelo Clássico é composto por autores teóricos normativos/dedutivos e por teóricos positivistas/indutivos. Os teóricos normativos/dedutivos são reformadores e defendem a primazia de novas teorias e abordagens, dentre esses, merecem destaque: Paton (1922), Sweeney (1936), MacNeal (1939), Edwards \& Bell (1962), Moonitz (1961) e Sprouse \& Moonitz (1962). Já os teóricos positivistas/indutivos buscam efetuar comparações e expor elementos, desenvolvendo teorias coerentes a partir da prática existente. Dentre os positivistas, destacam-se: Hatfield (1927), Gilman (1939), Paton \& Littleton (1940), Littleton (1953) e Ijiri (1975). Há, também, os autores motivados pelo desejo de analisar, explicar e avaliar o que os contadores operacionalizam, dentre eles, destacam-se: Canning (1929) e Alexander (1950) (AAA, 1977).

O Modelo de Utilidade da Decisão é voltado para o reconhecimento explícito do princípio da utilidade, sendo este modelo composto por Modelos de Decisão e por Tomadores de Decisão. Nos Modelos de Decisão, as informações relevantes são isoladas e as variáveis contábeis são comparadas com os dados necessários à execução dos modelos de decisão. Já os Tomadores de Decisão analisam as reações dos tomadores de decisão junto aos dados contábeis.

De forma objetiva, o SATTA fez um resumo do Modelo de Decisão, pertencente ao Modelo de Utilidade da Decisão, no qual constam conceitos do objetivo e das características qualitativas da informação financeira útil, semelhantes àqueles apresentados na recente Estrutura Conceitual, no capítulo 2 do referido documento, em fase de conclusão pelo IASB, conforme demonstra o SATTA, elaborado pela AAA (1977, p. 13, tradução nossa):

1. O objetivo principal da contabilidade é fornecer informações financeiras sobre os assuntos econômicos de uma entidade para as partes interessadas, para uso na tomada de decisões. Esta afirmação objetiva é uma premissa que a maioria das pessoas parece aceitar, sujeita a pequenas variações. Mas pode não ser adequada, a menos que se interprete amplamente as "decisões" (...).

2. Para ser útil na tomada de decisões, a informação financeira deve possuir várias qualidades normativas. A principal é a relevância de um determinado elemento para uma decisão particular, considerando uma mensuração específica. A segunda qualidade mais importante é a confiabilidade da mensuração, relativa a um dos elementos. Objetividade, verificabilidade, ausência de viés e exatidão são termos relacionados a qualidade de confiabilidade. Outras qualidades, como comparabilidade, compreensão, oportunidade e economia, também são enfatizadas. Um conjunto de qualidades desejáveis é usado como critério para avaliação de métodos contábeis alternativos. 
3. O critério de relevância é usado para selecionar o(s) atributo(s) de um objeto ou evento a ser enfatizado no relatório financeiro. As informações sobre um atributo de um objeto ou evento são relevantes para uma decisão se o conhecimento desse atributo pode ajudar o tomador de decisões a determinar cursos alternativos de ação ou a avaliar um resultado de um curso de ação alternativo. A seleção do atributo mais relevante para uma decisão requer familiaridade com os processos de decisão do usuário dos dados financeiros. Processos de decisão "modelagem" são, muitas vezes, úteis para os teóricos da contabilidade.

$[\ldots]$

Vale destacar este Modelo, pois os conceitos supracitados possuem similitude em relação àqueles atualmente utilizados mundialmente, segundo o processo de convergência das Normas Internacionais de Contabilidade, sob orientações do IASB. Sendo assim, esse conteúdo será aprofundado ao longo deste estudo, durante a análise comparativa de quais conceitos se mantiveram e auxiliaram na elaboração e consolidação da atual Estrutura Conceitual, adotada por diversos países (e.g., ZEFF, 2012), com o objetivo de alcançar a convergência contábil.

Por fim, o Modelo da Economia da Informação utiliza conceitos advindos da teoria econômica, no intuito de identificar quais informações são necessárias à tomada de decisões econômicas, considerando-se o critério de custo-benefício. O modelo é composto pelo Caso Individual Único e pelo Caso Multi-Individual. No Caso Individual Único, a demanda por informações é vista sob a perspectiva da capacidade de melhorar a qualidade da escolha a ser efetuada e suas análises buscam determinar a maximização esperada da utilidade.

Para o Caso Multi-Individual, as informações financeiras são consideradas como bem público. Nesse caso, a demanda de usuários heterogêneos aumenta a possibilidade de subprodução ou superprodução de informações. Sob a perspectiva econômica, considera-se a economia do bem-estar e as análises baseiam-se na solução ótima de Pareto e que as dificuldades na distribuição de informações contemplam conceitos econômicos como carona, seleção adversa e risco moral.

\subsection{Conceptual Framework for Financial Reporting}

O Financial Accounting Standards Board (FASB) foi criado em 1973, como sucessor da APB, sem finalidade lucrativa e com o objetivo de elaborar os Princípios Contábeis Geralmente Aceitos nos EUA (US GAAP). No âmbito mundial, o Internationtal Accounting Standards Board (IASB) foi criado em 2001, fruto do International Accounting Standards Committee (IASC), encarregado por emitir as International Financial Reporting Standards (IFRS) (ZEFF, 2012). Para Alexander, Britton e Jorissem (2007), o IASB conquistou força devido à exigência da União Europeia no que diz respeito à adoção das IFRS até 2005.

No ano de 2004, o FASB e o IASB se uniram para rever a Estrutura Conceitual. Em 2010, foi lançado um documento contendo o conceito do objetivo dos Relatórios Financeiros de Propósitos Gerais (RFPG) e das características qualitativas da informação financeira útil. Na ocasião, suspenderam-se os trabalhos para que outros projetos pudessem ser desenvolvidos e o tema foi retomado, em 2012, pelo IASB.

Posteriormente, em julho de 2013, foi publicado o Discussion Paper (DP), para revisão da Estrutura Conceitual. O intuito era obter manifestações de toda e qualquer parte interessada, com comentários favoráveis ou não, para que, após o estudo das manifestações, o IASB realizasse uma segunda análise e uma conclusão do documento sobre a Estrutura Conceitual.

O prazo para manifestações findou-se em janeiro de 2014. Na ocasião, foram enviadas 220 (duzentas e vinte) cartas-comentários, que foram analisadas pelo IASB. Posteriormente, foram realizadas mesas-redondas e ações de sensibilização, abertas para a contribuição de todos os países, no intuito de abarcar todas as semelhanças e peculiaridades locais e de consolidar um entendimento que fosse aplicável à maioria dos países, mesmo que de forma genérica, em algumas situações.

O resultado das referidas medidas foi o Exposure Draft - ED/2015/3 da Estrutura Conceitual, datado de 20 de outubro de 2015, no qual o IASB divulgou uma minuta de exposição referente ao entendimento sobre os temas discutidos, os quais resultaram na Estrutura Conceitual do IASB, emitida em março de 2018, após cumpridas as deliberações dos Conselheiros do IASB.

Diante do normativo mais recente sobre o entendimento do IASB sobre a Estrutura Conceitual, por meio do Basis for Conclusions on the Exposure Draft Conceptual Framework for Financial Reporting - ED/2015/3, este estudo dará destaque ao capítulo 2, que trata das Características Qualitativas da Informação Financeira Útil. No que tange ao tema, segundo Niyama e Silva (2013), as características qualitativas da informação financeira útil podem ser resumidas conforme demonstra a Figura 2: 
Figura 2: Características Qualitativas da Informação Financeira Útil

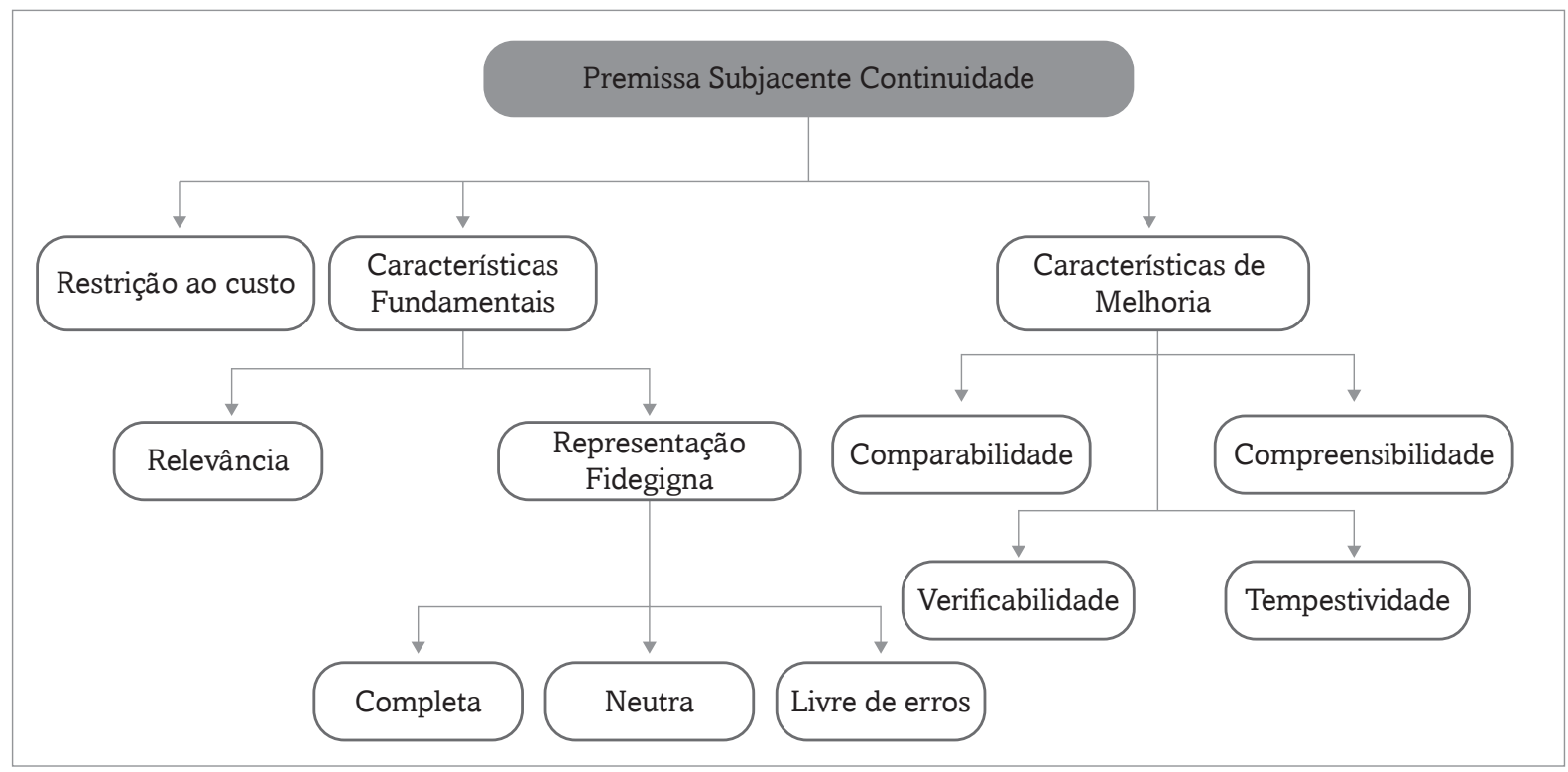

Fonte: Adaptado de Niyama e Silva (2013)

Destaca-se que, no ED/2015/3, tal estrutura se mantém. Sendo assim, a estrutura provavelmente será mantida, também, no documento final e definitivo a ser divulgado pelo IASB e será amplamente aplicada pelos países que optarem pela convergência às IFRS.

\section{METODOLOGIA}

Para que a pesquisa seja concretizada, torna-se necessária a utilização de métodos e técnicas adotados entre os conhecidos procedimentos científicos (MATIAS-PEREIRA, 2016). O presente artigo trata de uma pesquisa descritiva e documental, por observar e descrever conceitos contábeis identificados em documentos relativos à teoria da contabilidade.

O SATTA, em detrimento de documentos como ASOBAT e APB4, foi adotado na pesquisa devido à importância acadêmica do trabalho e à busca para estabelecer o fechamento de apenas uma teoria da contabilidade. Além disso, objetivou-se verificar a importância desta produção, relativa a Teoria da Contabilidade, na construção da Estrutura Conceitual, emitida pelo IASB.

O estudo efetua a análise de conteúdo das informações constantes no Statement on Accounting Theory and Theory Acceptance (SATTA) e no Conceptual Framework for Financial Reporting, em fase de conclusão pelo International Accounting Standards Board (IASB), associando de forma comparativa tais informações com a teoria contábil, no que tange especificamente aos conceitos relativos ao objetivo e às características qualitativas da informação contábil. No que tange à abordagem reflexiva - o objetivo dos relatórios financeiros, as características qualitativas e os conceitos explícitos -, as produções analisadas permitiram o fortalecer do conhecimento contábil e as teorias inerentes para o desenvolvimento de pesquisas nesta área de atuação, ao buscar evidenciar itens comuns entre eles, que compõem a Teoria da Contabilidade, e que influenciaram na Estrutura Conceitual, que já está sendo adotada pelos países que optaram por aderir ao projeto de convergência contábil proposto pelo IASB.

\section{ANÁLISE CONCEITUAL DO OBJETIVO DO RELATÓRIO FINANCEIRO E DAS CARACTERÍSTICAS QUALITATIVAS DA INFORMAÇÃO FINANCEIRA ÚTIL}

No presente capítulo, será efetuada a comparação entre o objetivo e as características qualitativas da informação financeira útil presente nos documentos SATTA e Conceptual Framework for Financial Reporting do IASB, a fim de identificar o processo de evolução e amadurecimento dos conceitos que fundamentam a Teoria da Contabilidade.

\subsection{Objetivo do Relatório Financeiro}

Para a AAA (1977, p. 1), por meio do SATTA, o objetivo central da contabilidade é a "prestação sistemática de dados econômicos sobre relatórios da entidade". Esta prestação sistemática é fornecida para os indivíduos e grupos externos à entidade que relata, para auxiliar em seus processos de tomada de decisão. Whittington (2008) enfatiza a dificuldade de atender às necessidades do usuário por meio das informações contábeis. 
Segundo o Conceptual Framework for Financial Reporting, recentemente divulgado pelo IASB (2015a, p. 13), o objetivo dos relatórios financeiros para fins gerais é fornecer informações financeiras de propósito geral sobre a entidade que sejam úteis aos tomadores de decisão (e.g., investidores e credores). Assim, considerando tais conceitos como os conceitos que tratam do objetivo da contabilidade e do relatório financeiro, segue o Quadro 1:

Quadro 1: Objetivo do Relatório Financeiro

\section{SATTA (1977)}

Fornecer informações econômicas úteis para os indivíduos e grupos externos à entidade.

\section{IASB (2015a)}

Fornecer informações que são úteis para o usuário das demonstrações financeiras.

Fonte: Elaboração própria.

Diante da disposição do Quadro 1, observa-se que, em 1997, já se identificava um consenso no fornecimento de informações para os usuários externos. No SATTA, o conceito era tratado de forma mais ampla, por citar o fornecimento de informações econômicas como o objetivo da contabilidade. Atualmente, o IASB apresenta o fornecimento de informações úteis como o objetivo dos relatórios financeiros de forma mais específica.

No SATTA, o texto fez referência à prestação de dados econômicos sobre relatórios da entidade que sejam úteis para o usuário externo. O IASB, atualmente, manteve o conceito ao citar que o relatório financeiro precisa fornecer informações não apenas econômicas, mas informações da entidade que sejam úteis para o usuário.

Assim, observa-se que o objetivo do relatório financeiro veio, ao longo do tempo, se legitimando, posto que se manteve até os dias atuais. Niyama e Silva (2013) expõem a necessidade de utilidade da informação contábil. Utilidade no que diz respeito à tomada de decisão por parte do usuário da informação contábil.

Nesse sentido, Mirza, Holt e Orrell (2010) afirmam que o IASB conseguiu, nos últimos anos, uma maior participação dos usuários da informação em diversos países, resultando em maior reconhecimento e utilização das IFRS. Por sua vez, Hope e Vyas (2016) destacam que os relatórios financeiros são importantes para empresas, auxiliando, e.g., nas fontes de financiamento.

\subsection{Características Qualitativas da Informação Financeira Útil}

Segundo a AAA (1977, p. 13), por meio do SATTA, as características qualitativas, descritas no item 2.1 desse estudo, podem ser resumidas em qualidades normativas e em outras qualidades, conforme a Figura 3.

Figura 3: Características qualitativas - SATTA

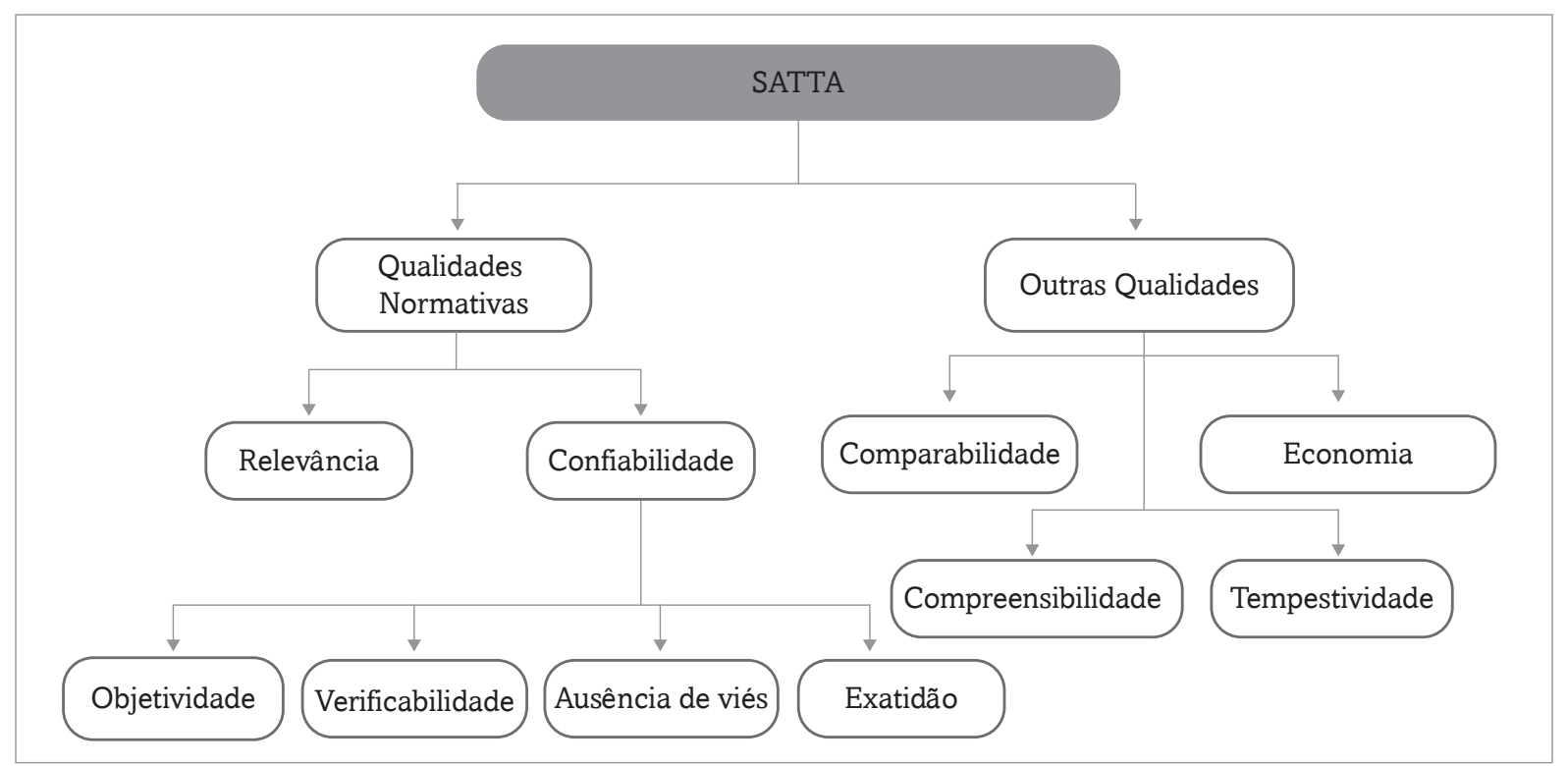

Fonte: Elaborado a partir de AAA (1977).

Ao efetuarmos a comparação da Figura 3 com a Figura 2, ressalta-se que, anteriormente, segundo o entendimento apresentado pela AAA (1977), por meio do SATTA, as qualidades normativas se classificavam em relevância e confiabilidade, no qual o critério da relevância era o principal critério para identificar a necessidade de mensurar determinada 
informação. Em seguida, caso a informação fosse identificada como relevante, se observava a confiabilidade da informação (segundo critério).

Segundo o entendimento atual do IASB, tais qualidades normativas são denominadas características fundamentais, com, também, 2 (dois) critérios: relevância e representação fidedigna. Niyama e Silva (2013) afirmam que as características fundamentais são mais importantes, sendo que as outras são apenas complementares. Para viabilizar a análise do critério da relevância, segue o Quadro 2, que dispõe dos conceitos sob a perspectiva de cada documento de análise da pesquisa:

Quadro 2: Conceito de Relevância

\section{SATTA (1977, p. 16) - Relevância}

"Um atributo de um objeto é relevante para uma decisão se o conhecimento dele ajudar o usuário a avaliar o resultado de uma ou mais alternativas de ação a serem consideradas."
IASB - (2015a, p. 42)

"A informação só é relevante se efetivamente fizer diferença nas decisões dos utilizadores."

Fonte: Elaboração própria.

Diante do Quadro 2, observa-se que a essência do conceito se manteve em ambos os documentos analisados. Assim, pode-se afirmar que o conceito da relevância se legitimou ao longo do tempo e se mantém até os dias atuais. Mirza, Holt e Orrell (2010) acrescentam que o termo está estreitamente relacionado com o termo materialidade e com o termo como limiar ou ponto de corte quanto às informações cuja distorção poderia influenciar as decisões dos usuários dos demonstrativos financeiros.

Quanto aos conceitos de confiabilidade e representação fiel, primeiramente, cabe resgatar ambos os conceitos para identificar em quais pontos eles se diferem ou se podem ser considerados como semelhantes. Nesse sentido, segue o Quadro 3:

Quadro 3: Conceito de Confiabilidade e Representação Fidedigna

SATTA $(1977$, p. 16) - Confiabilidade

"Confiabilidade é aquela qualidade que permite que os usuários da informação dependam dela, de modo que tenham confiança de que o item representa o que se propõe representar."
IASB (2015a) - Representação Fidedigna

Representa fielmente os fenômenos que pretende representar, sendo a informação completa, neutra e livre de erros.

\section{Fonte: Elaboração própria.}

Segundo o IASB (2015b, p. 115), a Estrutura Conceitual de 1989 apresentava o termo confiabilidade como informação "livre de erros e preconceitos materiais e que pode ser compreendida pelos usuários como uma informação que possa representar fielmente o que ela se propõe a representar”. Na ocasião, a Estrutura Conceitual também abordava a substância sobre a forma, a neutralidade, a prudência e a integralidade como aspectos da representação fiel.

Assim, observam-se semelhanças entre as definições, contudo, elas não se equiparam como sinônimos, havendo, portanto, algumas distinções. Ao longo da revisão da Estrutura Conceitual de 1989, diante das tentativas infrutíferas de definir o termo "confiabilidade", o IASB apresentou claramente a definição do conceito de "confiabilidade" e, no mesmo documento, propôs alterar o termo para "representação fidedigna", posto que a definição de confiabilidade, disposta na Estrutura Conceitual e apresentada no Quadro 3, não denotava apenas a confiabilidade da informação, possuindo maior amplitude, conforme detalhado no documento da Estrutura Conceitual (IASB, 2015b).

Diante do exposto, conclui-se que confiabilidade e representação fidedigna não são tratadas como iguais, no SATTA e na Estrutura Conceitual. A definição apresentada pelo IASB não representava precisão da informação, como o significado de confiabilidade demonstrado no SATTA, sendo necessária a alteração da denominação para "representação fidedigna”. Para o IASB (2015a), a informação financeira, para ser útil, precisa representar fielmente os fenômenos relevantes para o usuário. Além das Características Qualitativas Fundamentais, denominadas de qualidades normativas no SATTA, são consideradas as Características de Qualitativas de Melhoria, denominadas de Outras Qualidades no SATTA.

No que tange às outras qualidades da informação útil, no SATTA, essas eram compostas pela comparabilidade, compreensibilidade, tempestividade e economia. Já as características de melhorias, segundo o entendimento do IASB, englobam a comparabilidade, verificabilidade, tempestividade e compreensibilidade, conforme consolidado no Quadro 4: 
Quadro 4: Outras qualidades e Características de Melhoria

\begin{tabular}{|c|c|}
\hline SATTA (1977, p. 13) - Outras Qualidades & IASB - (2015a) - Características de Melhoria \\
- Comparabilidade; & - Comparabilidade; \\
- Compreensibilidade; & - Compreensibilidade; \\
- Tempestividade e & - Tempestividade e \\
- Economia. & - Verificabilidade. \\
\hline
\end{tabular}

Fonte: Elaboração própria.

Diante da análise do Quadro 4, observa-se que os itens que compõem as outras qualidades e as características de melhoria são semelhantes. Mirza, Holt e Orrell (2010), e. g., reportam que a compreensibilidade diz respeito à facilidade de compreensão da informação por parte do usuário com conhecimento razoável sobre a empresa e contabilidade. Martins et al. (2014) afirmam que a tempestividade é observada quando sua disponibilidade pode influenciar nas decisões do usuário. Já o termo comparabilidade, de acordo com o IASB (2015a), é a característica que permite que o usuário identifique e compreenda diferenças e semelhanças entre itens, sendo uma meta para a contabilidade.

As distinções ocorrem com os termos economia e verificabilidade. Cabe destacar que a economia, antes considerada como outra qualidade, na nova Estrutura Conceitual do IASB (2015b), passou a ser uma restrição (a do custo-benefício), na qual os custos precisam ser justificados pelos benefícios intrínsecos à divulgação. Quanto à verificabilidade, esse item era considerado uma característica relacionada à confiabilidade, segundo o SATTA. Para o IASB, a verificabilidade passou a ser uma característica de melhoria.

Já o IASB (2015a) apresenta a verificabilidade como característica na qual diferentes observadores podem chegar a um consenso, embora não necessariamente a um acordo completo, podendo ser direta ou indireta. Por sua vez, Niyama e Silva (2013) atentam, ainda, para a associação do custo e benefício da informação contábil e para a dificuldade de encontrar os benefícios de reporta-la.

\section{CONSIDERAÇÕES FINAIS}

Este artigo buscou efetuar uma análise evolutiva da Teoria da Contabilidade, no que tange ao objetivo e às características qualitativas da informação contábil, por meio de análise comparativa entre os documentos SATTA e Estrutura Conceitual do IASB. O intuito foi identificar o processo de evolução e amadurecimento dos conceitos que fundamentam a Teoria da Contabilidade.

Ao longo da análise dos conceitos e em resposta à questão de pesquisa, identificou-se que os conceitos do objetivo e das características da informação contábil praticamente não se alteraram ao longo dos anos e que se mantiveram legitimados até os dias atuais. Cabe ressaltar que o conceito de confiabilidade foi aprimorado para representação fidedigna, posto que a definição do conceito de confiabilidade apresentava um sentido mais amplo do que sua denominação.

Outro fundamento importante que foi identificado se refere às outras qualidades, pois a característica da economia se tornou restrição e a verificabilidade, antes considerada como característica da confiabilidade, hoje, é classificada como uma característica de melhoria. O termo verificabilidade atenta para a necessidade de se oferecer aos usuários uma informação contábil com maior qualidade.

Sendo assim, este artigo evidenciou que, em termos gerais, muitos conceitos debatidos desde o início do Século XX, apontados pela AAA, vieram se consolidando, passaram por aprimoramentos e foram legitimados nas Normas Internacionais de Contabilidade, que, atualmente, são discutidas a nível global.

Para pesquisas futuras, sugerimos que seja dada continuidade à análise evolutiva de demais conceitos da Teoria da Contabilidade por meio de outros documentos (além do SATTA) que não foram tratados neste estudo, posto que é de extrema importância para o campo das Ciências Contábeis compreender o processo de amadurecimento e consolidação da Teoria da Contabilidade, bem como identificar como se deu o seu processo de revolução científica nesta área de conhecimento.

\section{REFERÊNCIAS}

ALEXANDER, David; BRITTON, Anne; JORISSEN, Ann. International financial reporting and analysis. United Kingdom: Cengage Learning EMEA, 2007.

AMERICAN ACCOUNTING ASSOCIATION. Committee to prepare a statement of basic accounting theory. A statement of basic accounting theory. Florida: American Accounting Association, 1966.

. COMMITTEE ON CONCEPTS; STANDARDS FOR EXTERNAL FINANCIAL REPORTS. Statement on accounting theory and theory acceptance. Florida: American Accounting Association, 1977.

AMERICAN INSTITUTE OF CERTIFIED PUBLIC ACCOUNTANTS. Accounting Principles Board. Basic Concepts and Accounting Principles underlying Financial Statements of Business Enterprises. Statement n.4. New York, NY: 1970.

BRADBURY, M. E. Implications for the Conceptual Framework Arising from Accounting for Financial Instruments. Abacus, v.39, n.3, p.388-397, 2003. 
BUBLITZ, Bruce; PHILIPICH, Kirk; BLATZ, Robert. An Example of the Use of Research Methods and Findings as an Experiential Learning Exercise in an Accounting Theory Course. Journal of Instructional Pedagogies, v.16, p.1-11, 2015.

CHAMBERS, R. J. “The Development of Accounting Theory” in R. J. Chambers, L. Goldberg, and R. L. Mathews, eds. The Accounting Frontier. Melbourne: Cheshire, 1 ed. p.18-35, 1965.

DENNIS, I. D. A Philosophical Investigation into the Conceptual Framework for Accounting. [s.l.] University of London, 2006.

EL-ESSELY, M. A. M. The Conceptual Framework for Financial Accounting and Reporting in the Developing Countries: Empirical Study of the Unified Accounting System in Egypt. [s.l.] The City University Business School, 1987.

GORE, P. The FASB Conceptual Framework Project 1973-1985: An Analysis. August, 1989.

GORDON, Elizabeth A. et al. The IASB's Discussion Paper on the Conceptual Framework for Financial Reporting: A Commentary and Research Review. Journal of International Financial Management \& Accounting, v.26, n.1, p.72-110, 2015.

HENDRIKSEN E. S.; VAN BREDA, Michael F. Teoria da contabilidade. Tradução Antonio Zoratto Sanvicente. São Paulo: Atlas, 1999. 550p.

HINES, R. D. The FASB's conceptual framework, financial accounting and the maintenance of the social world. Accounting, Organizations and Society, v.16, n.4, p.313-331, 1991.

HOPE, Ole-Kristian; VYAS, Dushyantkumar. Private Company Finance and Financial Reporting. Forthcoming, Accounting and Business Research; Rotman School of Management Working Paper No. 2928730. Toronto, 2016.

IASB. Conceptual Framework for Financial Reporting. ED/2015/3. London, Out. 2015(a).

$2015(\bar{b})$.

Basis for Conclusions on the Exposure Draft Conceptual Framework for Financial Reporting. ED/2015/3. London, May

IUDÍCIBUS, Sérgio; BEUREN, Ilse Maria; DOS SANTOS, Vanderlei. Ensino da Teoria da Contabilidade nos Programas de Pós-Graduação de Ciências Contábeis do Brasil. Revista Universo Contábil, v.12, n.4, p.06-29, 2016.

p.6, 2015 .

MARTINS, Eric Aversari. Estudando e Pesquisando Teoria: O Futuro Chegou?. Revista Universo Contábil, v.11, n.1,

KAM, Vernon. Accounting theory. New Yourk: Wiley, 1990.

PATON, William Andrew. Accounting theory, with special reference to the corporate enterprise. Ronald Press, 1922.

n. 3, p.1-156, 1940 .

LITTLETON, A. C. An Introduction to Corporate Accounting Standards. American Accounting Association. Monograph

PEASNELL, Kenneth V. Statement of Accounting Theory and Theory Acceptance: A Review Article by KV Peasnell. Accounting and Business Research, v.8, n.31, p.217-225, 1978.

MARTINS, Vinícius Gomes et al. Níveis Diferenciados de Governança Corporativa e a Qualidade da Informação Contábil Durante o Processo de Convergência às Normas Internacionais de Contabilidade. ConTexto, v.14, n.27, p.23-42, 2014.

MATIAS-PEREIRA, José. Metodologia da Pesquisa Cientifica. 4.ed. São Paulo: Atlas, 2016.

MIRZA, Abbas A.; HOLT, Graham; ORRELL, Magnus. International Financial Reporting Standards (IFRS) Workbook and Guide: Practical Insights, Case Studies, Multiple-choice Questions, Illustrations. New Jersey: John Wiley \& Sons, 2010.

NIYAMA, J. K. Teoria Avançada da Contabilidade. São Paulo: Atlas, 2014.

SILVA, C. T. Teoria da Contabilidade. 3.ed. São Paulo: Atlas, 2013.

NIYAMA, J. K. et al. Princípios contábeis europeus e brasileiros: uma abordagem comparativa. Contabilidade, Gestão e Governança, v.2, n.1, p.111-132, 1999.

NUSSBAUMER, N. Does the FASB's conceptual framework help solve real accounting issues? Journal of Accounting Education, v.10, n.1, p. 235-242, 1992.

OLIVEIRA, A. F. DE O. Evolução da terminologia princípio contábil baseada na escola norte-americana. [s.l.] Dissertação (Mestrado em Ciências Contábeis), Programa Multiinstitucional e Inter-regional de Pós-Graduação em Ciências Contábeis da UnB, UFPB, UFPE e UFRN, Natal: UFRN, 173, p., 2003.

OLIVEIRA, H. C. DE; CARVALHO, R. M. DE. A Quarta e Sétima Diretivas da União Européia e suas Implicações sobre a Contabilidade Local do País-Membro: França. Salvador: EnAMPAD 2006, p. 16, 2006.

PAULO, E. Comparação da Estrutura Conceitual da Contabilidade Financeira. [s.l.] Universidade de Brasília, Universidade Federal da Paraíba, Universidade Federal de Pernambuco, Universidade Federal do Rio Grande do Norte, 2002.

RIAHI-BELKAOUI, Ahmed. Accounting theory. 5 ed. London: Thomson Learning, 2004. 598p.

SCHIPPER, K. Principles-based accounting standards. Accounting Horizons, v.17, n.1, p.61-72, 2003.

VATTER, William J. Postulates and principles. Journal of Accounting Research, v.1, n.2, p.179-197, 1963.

WHITTINGTON, Geoffrey. Fair value and the IASB/FASB conceptual framework project: an alternative view. Abacus, v.44, n.2, p.139-168, 2008.

XIAO, Z; PAN, A. Developing accounting standards on the basis of a conceptual framework by the Chinese government. The International Journal of Accounting, v.32, n.3, p.279-299, 1997. 
ZEFF, Stephen A. The Evolution of the IASC into the IASB, and the Challenges it Faces. The Accounting Review, v.87, n.3, p.807$837,2012$.

ZEFF, S. A. Some Junctures of in in the Evolution of the Process Principles Establishing the U.S.A.: 1917-1972. The Accounting Review, v.59, n.3, p.447-468, 1984.

ZEFF, S. A. The evolution of the conceptual framework for business enterprises in the United States. The Accounting Historians Journal, v.26, n.2, p.89-131, 1999.

ZEFF, S. A. The SEC rules historical cost accounting: 1934 to the 1970s. Accounting and Business Research, v.37, n. June 1933, p.49-62, 2007.

ZEFF, S. A. The objectives of financial reporting: a historical survey and analysis. Accounting and Business Research, v.43, n.4, p.262-327, 2013.

ZEFF, S. A. The Trueblood Study Group on the Objectives of Financial Statements (1971-73): A Historical Study. [S.1.: s.n.]. 